\title{
Relationship between personal, socio-ecomonmic and psychological characteristics of dairy farmers with their entrepreneurial behaviour
}

\author{
B.L. PISURE, B.M. THOMBRE AND C.R. JAMADAR
}

\begin{abstract}
The study was conducted in Latur district. Two tahsils and four villages from each tahsil were selected randomly. Fifteen dairy farmers from eight villages were selected to comprise a sample of 120 respondents. In view with above objectives the multistage random sampling was used to select district, tahsil, village and dairy farmers. Collected data were classified, tabulated and analyzed by using statistical methods like frequency, percentage, mean, standard deviation, correlation co-efficient and multiple regressions. The findings pertaining to the relationship of different selected personal, socio-economical and psychological characteristics of dairy farmers with their entrepreneurial behaviour revealed that independent variables namely dairy farming experience, education, land holding, annual income, herd size, extension contact, social participation, use of sources of information and market orientation had positive and highly significant and whereas, occupation, family size of the dairy farmers had showed non-significant correlation with entrepreneurial behaviour of the respondents.
\end{abstract}

KEY WORDS : Relationship, Entrepreneurial behaviour, Socio-ecomonmic characteristics, Psychological characteristics, Dairy farmers

HOW TO CITE THIS PAPER : Pisure, B.L., Thombre, B.M. and Jamadar, C.R. (2015). Relationship between personal, socio-ecomonmic and psychological characteristics of dairy farmers with their entrepreneurial behaviour. Res. J. Animal Hus. \& Dairy Sci., 6(1) : 1-5. 